\title{
The Prognosis Value of PSPCI Expression in Nasopharyngeal Cancer
}

This article was published in the following Dove Press journal:

Cancer Management and Research

\author{
Huocong $\mathrm{He} \mathbb{D}^{1, *}$ \\ Lurong Zhang $\mathbb{D}^{1, *}$ \\ Keyu Lin (iD) ${ }^{1, *}$ \\ Zhengrong Huang (iD ${ }^{2}$ \\ Yan Zhou id ${ }^{3}$ \\ Shaojun Lin $\mathbb{D}^{4}$ \\ Ying Su $\mathbb{1}^{1}$ \\ Jianru Pan $\mathbb{D}^{5}$ \\ 'Laboratory of Radiation Biology, Fujian \\ Cancer Hospital \& Fujian Medical \\ University Cancer Hospital, Fuzhou, \\ Fujian, 350014, People's Republic of \\ China; ${ }^{2}$ Department of Integrative \\ Medicine, Fujian Cancer Hospital \& Fujian \\ Medical University Cancer Hospital, \\ Fuzhou, Fujian, 350014, People's Republic \\ of China; ${ }^{3}$ Department of Epidemiology, \\ Fujian Cancer Hospital \& Fujian Medical \\ University Cancer Hospital, Fuzhou, \\ Fujian, 3500 I4, People's Republic of \\ China; ${ }^{4}$ Department of Radiation \\ Oncology, Fujian Cancer Hospital \& \\ Fujian Medical University, Fuzhou, Fujian, \\ 3500 I4, People's Republic of China; \\ ${ }^{5}$ College of Biological Science and \\ Engineering, Fuzhou University, Fuzhou, \\ Fujian, 350002, People's Republic of \\ China
}

*These authors contributed equally to this work
Background: Paraspeckle component 1 (PSPC1) is overexpressed in various cancer and correlated with poor survival in the patients. However, little is known about its expression and role in the progression of nasopharyngeal carcinomas (NPC). The purpose of this study is to examine PSPC1 expression in NPC and explore its role in clinical prognosis of radiation therapy.

Methods: The association of PSPC1 expression with clinicopathological features of 109 NPC patients was examined using partial correlation analysis. Cancer tissues were obtained prior to clinical treatment. All cases were diagnosed and pathologically confirmed to be poorly differentiated or undifferentiated NPC without distant metastasis. The patients were then treated with radiation and followed-up. Survival analysis was performed.

Results: Partial correlation analysis revealed that the PSPC1 expression in NPC was correlated with N classification, recurrence, prognosis and radiosensitivity in NPC patients, but not with the gender, age, pathohistological pattern, clinical stage, and $\mathrm{T}$ classification. The overexpression of PSPC1 was detected in 64 samples (58.72\%). Kaplan-Meier survival analysis revealed that the overall survival (OS) was longer in NPC patients with PSPC1 low expression than that in those with PSPC1 high expression. Moreover, patients with the overexpression of PSPC1 had a low progression-free survival and distant metastasis-free survival rate, compared to those who had a low expression of PSPC1. Although not statistically significant, patients with high expression of PSPC1 had a lower locoregional recurrence-free survival rate than those with low expression, and the curves between the two groups was well separated.

Conclusion: PSPC1 overexpression was associated with poor prognosis for NPC, which might be a novel useful biomarker to predict the response of NPC to radiation therapy and its clinical outcome.

Keywords: nasopharyngeal carcinoma, paraspeckle component 1, PSPC1, clinical prognosis, radiation, overexpression

\section{Introduction}

Nasopharyngeal carcinoma (NPC) is the most common primary malignancy in the nasopharynx ${ }^{1}$ and highly prevalent in southern China, reaching 20 cases per 100,000 people. ${ }^{2,3}$ The radiotherapy is currently the first choice of treatment of NPC. ${ }^{4,5}$ With the development of novel radiotherapy, such as intensity modulated radiation therapy (IMRT), the regional control rate of NPC with IMRT has reached nearly 90\%, with relatively satisfying progression-free survival (PFS) and overall survival (OS) for newly diagnosed patients with early stages. ${ }^{6-9}$ Unfortunately, about $20 \%$ of the patients suffer from radio-resistance and
Correspondence: Huocong He Cancer Hospital \& Fujian Medical University Cancer Hospital, Fuzhou, Fujian, 3500 14, People's Republic of China Email hconghe@I63.com

Jianru Pan

College of Biological Science and Engineering, Fuzhou University, Fuzhou, Fujian, 350002, People's Republic of China Email panjr@fzu.edu.cn
Cancer Management and Research 2021:13 328I-329| 
recurrence, ${ }^{10}$ the leading cause of NPC treatment failure. ${ }^{11,12}$ The mechanisms underlying NPC radioresistance have not been completely understood. ${ }^{13}$ There is no specific biomarker that could precisely predict the radiosensitivity for NPC. ${ }^{14}$

Paraspeckles are nuclear bodies, which located in the interchromatin space of the cell nucleus near to speckles. ${ }^{15}$ These bodies are mainly composed of three proteins, including paraspeckle component 1 (PSPC1), splicing factor glutamine- and proline-rich, (PSF) and non-POUdomain containing octamer-binding protein (p54nrb), and the scaffolding long noncoding RNA Neat $1 .{ }^{16}$ Knockdown of PSPC1 does not prevent paraspeckle formation, but PSF and $554 \mathrm{nrb}$ do. ${ }^{17}$

PSPC1, a paraspeckle biomarker identified in an aberrant 13q12.11 locus, plays a role in DNA damage, ${ }^{18}$ RNA editing, ${ }^{19}$ adipocytes differentiation ${ }^{20}$ and gene regulation. $^{21-23}$ PSPC1 upregulation has been identified in several cancers, including hepatocellular carcinoma, ${ }^{24}$ lung cancer and breast cancer. ${ }^{16}$ It has been confirmed that PSPC1 overexpression commonly occurred in the higher stage of liver, breast and lung cancers and associated with poor patient prognosis. ${ }^{16}$ However, the expression level of PSPC1 and its clinical value in NPC have not yet been investigated. Here, we examined the PSPC1 expression in tumor samples obtained from NPC patients prior to treatment, and conducted a retrospective study to assess the value of PSPC1 expression as a novel biomarker in the NPC prognosis and response to radiation therapy.

\section{Materials and Methods}

\section{Antibodies and Reagents}

Anti-PSPC1 polyclonal antibody was purchased from Abcam (cat\#: ab184123, Cambridge, USA). Elivision ${ }^{\mathrm{TM}}$ super HRP (Mouse/Rabbit) IHC kit (cat\#: Kit-9922), EDTA buffer (pH 9.0) (cat\#: MVS-0099) and Antibody Diluent buffer (cat\#: ABD-0030) were purchased from Maixin (Fuzhou, China).

\section{Ethical Statement}

This study was approved by the Ethical Review Committee of Fujian Cancer Hospital. Written informed consent with a detailed description of the purpose of the study was obtained from all participants. All subjects involved in this study agreed to publish related demographic and clinical features. All procedures were conducted in accordance with the Helsinki declaration. All experimental procedures described in this study were conducted in accordance with national and local laws, regulations and guidelines.

\section{Samples and Patients}

The studied cohort includes 109 paraffin-embedded NPC samples from patients (92 males and 17 females, with a median age of 47 years old, ranged 15-89) diagnosed between April and November in 2012 in Fujian Cancer Hospital, Fuzhou, Fujian China. All cases were clinically diagnosed and confirmed pathologically as poorly differentiated or undifferentiated primary NPC without distant metastasis at the time of the diagnosis. Pretreatment evaluation consisted of a detailed patient history and physical examination, whole blood counts, flexible fiberoptic endoscopic examination, urinalysis, blood chemistries, electrocardiogram, chest X-ray, bone emission computed tomography (ECT) scans, magnetic resonance imaging (MRI) scans of the head and neck, and ultrasound of liver and abdominal lymph nodes. CT scans and Positron emission tomography (PET) scans of the abdomen/chest were performed when clinically recommended. All cases were reclassified according to the 2017 American Joint Committee on Cancer (AJCC, 8th edition). All tumor samples were obtained by biopsy prior to radiotherapy or chemoradiation therapy. At the same time, 9 normal nasopharyngeal epithelia tissues as control.

\section{Immunohistochemical Analysis}

Immunohistochemical (IHC) analysis was performed to examine the expression levels of PSPC1 protein. After deparaffinization, the tissue sections were immersed in ethylenediaminetetraacetic acid (EDTA) buffer ( $\mathrm{pH} 9.0$ ) and subjected to $121{ }^{\circ} \mathrm{C}$ treatment for $1.5 \mathrm{~min}$ for antigen retrieval. The samples were subsequently immersed in 3\% $\mathrm{H}_{2} \mathrm{O}_{2}$ for $10 \mathrm{~min}$ to block endogenous peroxidase, and then incubated with anti-PSPC1 primary antibody diluted in antibody diluent buffer at $4{ }^{\circ} \mathrm{C}$ overnight. The slides were processed using an Elivision ${ }^{\mathrm{TM}}$ super Horseradish Peroxidase (HRP) (Mouse/Rabbit) IHC kit (cat\#: Kit9922, Maixin) according to the manufacturer's protocol, and counterstained using haematoxylin.

The expression level of PSPC1 was scored by assessing both percentage of positive cell population and staining intensity. Immunohistochemically stained sections were scored independently by two pathologists blinded to the clinical parameters. The immunoreactive scores of 
PSPC1 staining were calculated as reported previously. ${ }^{25}$ The staining intensity was scored as: no staining (score 0 ), light-yellow (score 1), yellowish-brown (score 2) and brown (score 3). Percentage of positive cells was graded as following: $<5 \%$ (score 0 ), $5-25 \%$ (score 1 ), $>25-50 \%$ (score 2), $>50-75 \%$ (score 3 ) and $>75 \%-100 \%$ (score 4). The combination (IHC score) of the intensity score and percentage score was used to represent the expression level of PSPC1 in the tissues. According to the IHC score, the expression level of PSPC1 is divided into - (negative), + (weak), ++ (moderate), +++ (strong). Finally, we defined IHC score,-+ as low level of PSPC1 expression (Low PSPC1 group) and,+++++ as high level of the expression (High PSPC1 group).

\section{Radiotherapy}

All patients were treated primarily with IMRT according to an IRB-approved institutional treatment protocol. ${ }^{26}$ The nodal masses and gross volumes (GTV) of primary tumors were obtained by MRI and/or CT. The high-risk clinical tumor volume (CTV) included the GTV plus $5-10 \mathrm{~mm}$ margin, encompassing the entire nasopharyngeal mucosa plus $5 \mathrm{~mm}$ sub-mucosal volume. CTV for potentially involved regions included the posterior part of pterygopalatine fossae, parapharyngeal space, nasal cavity, posterior ethmoid sinus, maxillary sinuses, skull base, cervical vertebra and anterior third of the clivus, inferior sphenoid sinus and the retropharyngeal lymph nodal and cavernous sinuses and regions from the base of skull to the cranial edge of the second cervical vertebra. CTV of the neck nodal regions were outlined according to the recommendations by the consensus CTV delineation protocol for head and neck malignancies. An additional 3-mm margin was added to create the planning tumor volume (PTV). Spinal cord, brainstem, optic nerves, parotid glands, chiasm, globes, lens, temporomandibular joints, temporal lobes, pituitary gland and mandible were contoured and set as organs at risk during optimization. Cumulative doses of the primary lesion ranged from 69.2 to $75.25 \mathrm{~Gy}{ }^{27}$

\section{Efficacy Evaluation}

Efficacy was evaluated according to RECIST (Response Evaluation Criteria in Solid Tumors) V.1.1 criteria (https:// recist.eortc.org/recist-1-1-2/). The patients with complete remission (CR) or partial remission (PR) after radiotherapy were classified as RS-NPC, and the patients with stable disease (SD) and disease progression (PD) as RRNPC.

\section{Patient Follow-Up}

All cases in this study have been followed up with established protocol till June 2016 or decease. The median follow-up time was 45.7 months (range, 2-51 months). After the completion of the radiotherapy, patients were followed up at 3-month intervals during the first 2 years, 6-month intervals from the 2nd year until the end of the fifth year, and annually thereafter or till the patients deceased. The follow-up includes flexible fiber optic endoscopy, ultrasound of liver and abdomen, chest X-ray and basic serum chemistry. Either CT and/or MRI of the head and neck was performed after the completion of treatment and then every 6 months.

\section{Statistical Analysis}

All statistical analyses were performed using the statistical software SPSS version 18.0 (SPSS, Inc.; Chicago, IL, USA). Comparisons of the distributions of sociodemographic and clinical stages of different PSPC1 expression groups were calculated by chi-square test. The overall survival (OS) time, progression-free survival (PFS) time, distant metastasis-free survival (DMFS) time and locoregional recurrence-free survival (LRRFS) time was estimated with the Kaplan-Meier method and compared using the Log rank test. Multivariate analysis using the Cox semiparametric method (proportional hazard model) was performed. $P$ values of statistical significance are represented as $* P<0.05,{ }^{*} P P<0.01$ and ${ }^{* * *} P<0.001$.

\section{Results \\ PSPCI Overexpression is Associated with NPC}

The expression levels of PSPC1 in 109 NPC tissues and 9 normal nasopharyngeal epithelial samples were determined with IHC. We firstly set up the IHC score criteria of the level of PSPC1 expression. According to the IHC score, the expression level of PSPC1 is divided into (negative), + (weak), ++ (moderate), +++ (strong) (Figure 1).

In 109 tumor samples, the positive rate of PSPC1 in tumor tissues is $93.58 \%(102 / 109)$, and only one out of 9 normal nasopharyngeal tissues $\left(11.11 \%, \chi^{2}=51.181, P=\right.$ 0.000) was found positive for PSPC1. Among 109 cases of NPC, 64 were found to be PSPC1 high expression (score + $+\sim+++)$, accounting for $58.72 \%(64 / 109)$ of cases studied, while in normal nasopharyngeal epithelial tissue, 0 were found to be PSPC1 high expression, the high 

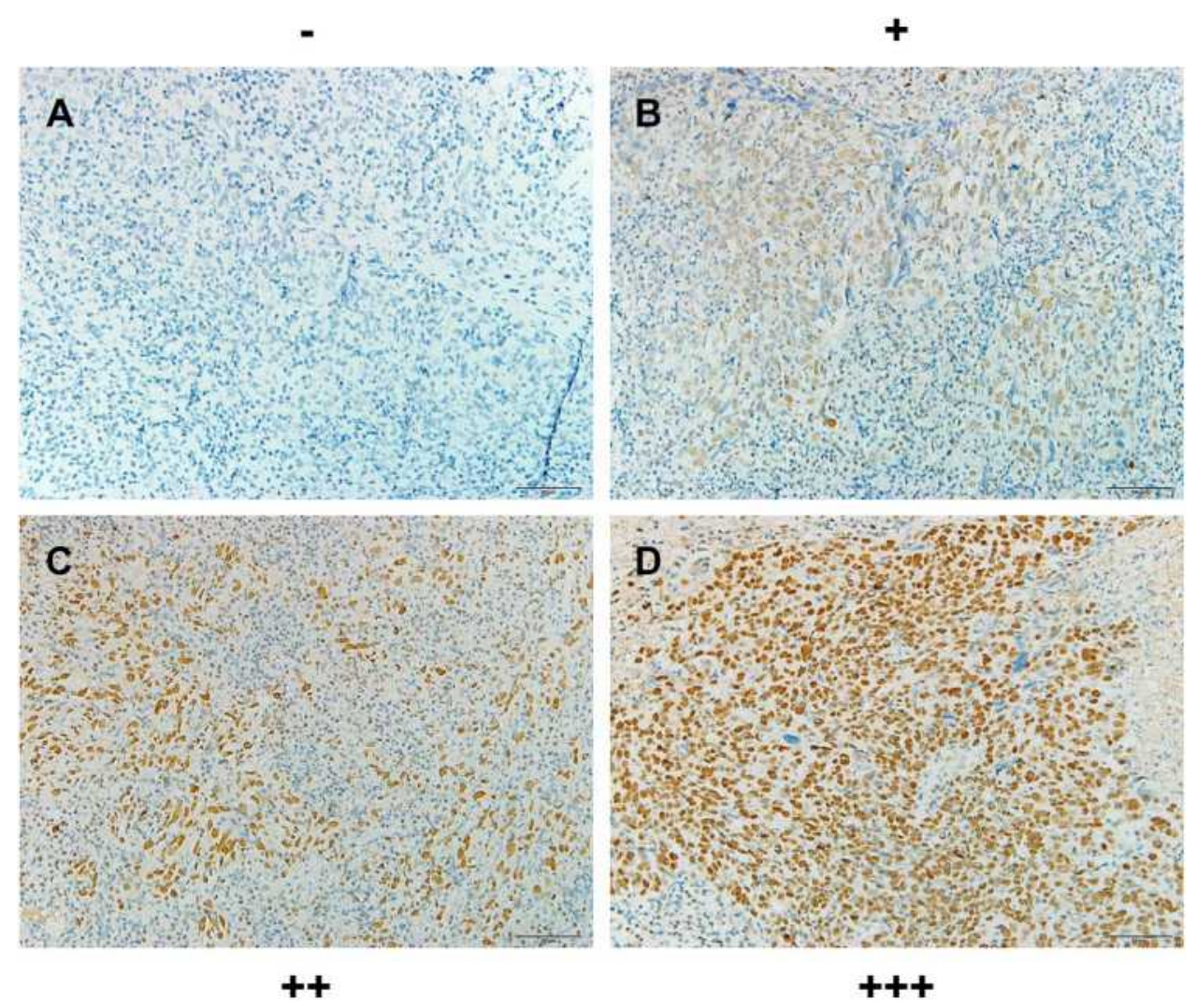

Figure I Scoring criteria for PSPCI expression in IHC.

Notes: Pictures of IHC processed at identical conditions for PSPCI expression were taken and scored. (A) - (negative). (B) + (weak). (C) ++ (moderate). (D) +++ (strong). Images were taken under light microscope $(200 \times)$. Scale bar $=50 \mu \mathrm{m}$.

expression rate is $0 \%(0 / 9)\left(\chi^{2}=11.547, P=0.001\right)$, suggesting that PSPC1 overexpression is associated with NPC (Figure 2).

\section{PSPCI Expression is Closely Related with Radiosensitivity of NPC}

To determine the correlation of PSPC1 expression with radiosensitivity of NPC, normal nasopharyngeal epithelial tissues (Normal), radiosensitive NPC (RS-NPC) and radioresistant NPC (RR-NPC) slides were compared to find the difference of their PSPC1 expression. As showed in Figure 3, the RS-NPC had a low expression level of PSPC1, while RRNPC had a high expression level of PSPC1, and Normal hardly expressed PSPC1. Moreover, it was found that the PSPC1 expression was correlated with radiosensitivity $(P=$ 0.010) in the NPC patients (Table 1).

\section{Correlation of PSPCI Expression with Clinical Parameters}

To examine the correlation between PSPC1 expression levels and clinical parameters of NPC, the 109 cases were grouped based on different clinical parameters. It was found that the PSPC1 expression was correlated with $\mathrm{N}$ classification $(P=0.038)$, recurrence $(P=0.014)$, prognosis $(P=0.040)$ and radiosensitivity $(P=0.010)$ in the NPC patients, but not with the gender $(P=0.299)$, age $(P=0.220)$, pathohistological pattern $(P=0.500)$, clinical stage $(P=0.469)$, T classification $(P=0.689)$ (Table 1$)$.

\section{Correlation of PSPCI Expression with Three-Year Outcome of NPC}

Clinically, four metrics are currently used to describe the outcomes of NPC: overall survival (OS), progression-free survival (PFS), locoregional recurrence-free survival (LRRFS) and distant metastasis-free survival (DMFS). The 3-year OS rate of the whole cohort was $88.9 \%$, and PFS, LRRFS and DMFS were $80.6 \%, 93.3 \%$ and $86.7 \%$, respectively in these NPC cases. Compared with PSPC1 high expression group, the PSPC1 low expression group had significantly higher OS $(95.6 \%$ vs $84.3 \% . P=0.034)$, PFS $(93.3 \%$ vs $71.9 \%$. $P=0.012)$ and DMFS rate $(95.6 \%$ vs $80.5 \% . P=0.029)$. Although LRRFS rate $(97.3 \%$ vs 


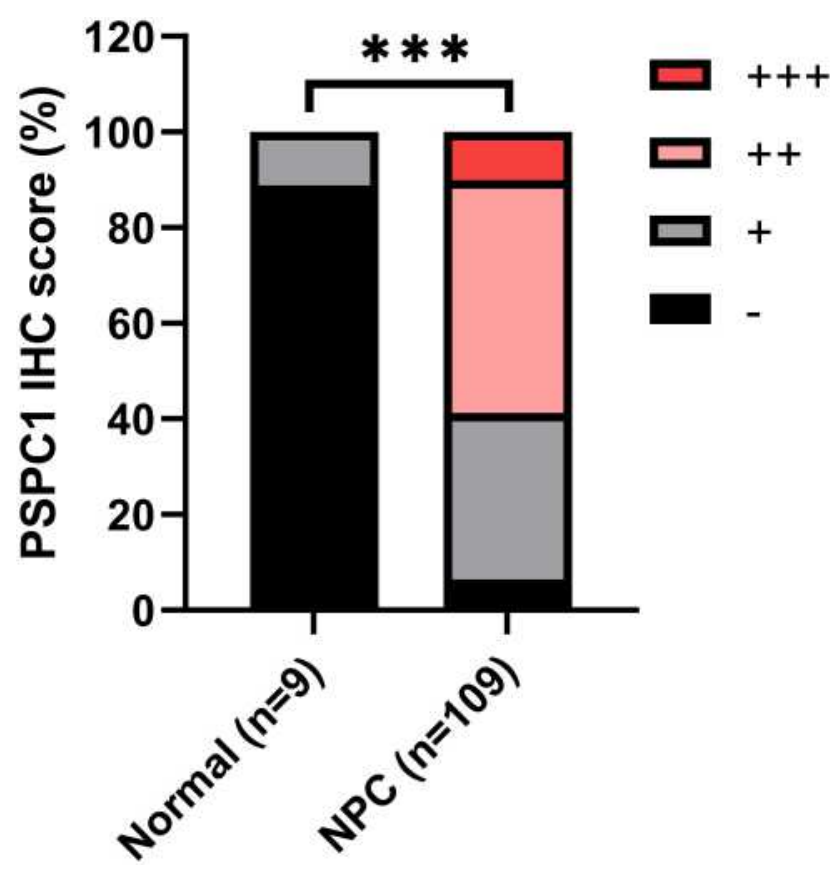

Figure 2 Percentage distribution of PSPCI IHC score in NPC tissues versus normal tissues.

Notes: The PSPCI staining intensity was scored and the distribution of IHC score was expressed as the percentage in NPC and normal tissues. Chi-square test was used to compare IHC scores in NPC tissues versus normal tissues. $* * * P<0.001$

$88.6 \% . P=0.085$ ) showed not any statistically significant difference, the curves between the two groups were well separated (Figure 4 and Table 2).

\section{Independent Risk Factors Affect the Outcomes of NPC}

Potential prognostic factors, including PSPC1 expression level, gender, age, pathohistological pattern, clinical stage, $\mathrm{T}$ classification, $\mathrm{N}$ classification were analyzed by using the Log rank test. As shown in Table 3, the gender, age, pathohistological pattern, clinical stage, $\mathrm{T}$ classification, $\mathrm{N}$ classification have not prognostic value for OS, PFS, LRRFS and DMFS ( $P>0.05$, respectively), while PSPC1 expression was found to be a potential predictor for OS, PFS and DMFS $(P=0.034,0.012$ and 0.029 , respectively), but not for LRRFS $(P=0.085)$.

To more accurately analyze the covariates and to avoid the interference among variates included in this study, the multivariate survival analyses was carried out. As showed in Table 4, PSPC1 expression was also found to be one of the most significant prognostic factors for OS, PFS and DMFS $(P=0.032,0.012$ and 0.026 , respectively), while LRRFS was not affected $(P=0.162)$. The multivariate analyses also indicated that gender, age, pathohistological pattern, clinical stage, $\mathrm{T}$ classification, $\mathrm{N}$ classification have not prognostic value for OS, PFS, LRRFS and DMFS $(P>0.05$, respectively). Both the univariate and multivariate models showed that PSPC1 expression was one significant prognostic factor for OS, PFS, and DMFS (Tables 3 and 4) in NPC patients.

\section{Discussion}

Radiotherapy is the first choice for the treatment of NPC. ${ }^{4}$ With the development of imaging and radiotherapy techniques, the progression rate, local recurrence rate and distant metastasis rate of NPC after radiotherapy have been significantly reduced. ${ }^{28}$ Especially after utilizing the IMRT method, the 3-year LRRFS and DMFS can reach more than $90 \%$ and $80 \%$, respectively. ${ }^{29}$ However, there are patients still developing regional recurrence and distal
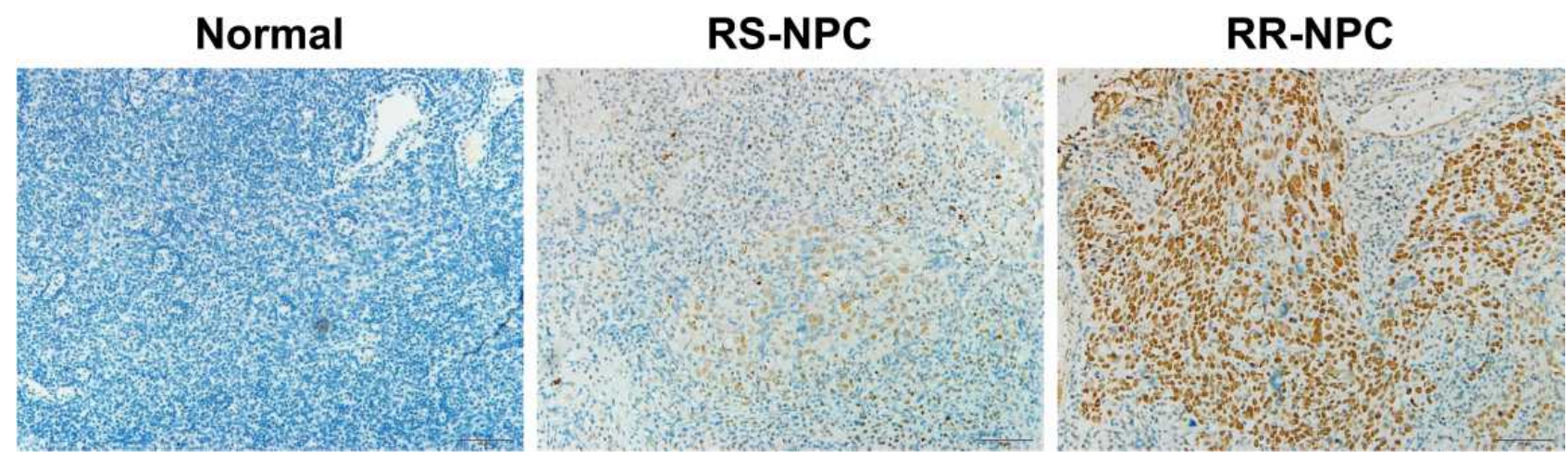

Figure 3 Differences of PSPCI expression among the normal tissues, radiosensitive NPC tissues and radioresistant NPC tissues.

Notes: Representative pictures of Normal (normal nasopharyngeal epithelial tissues). RS-NPC (radiosensitive NPC tissues) and RR-NPC (radioresistant NPC tissues) were taken after IHC under a light microscope. The staining intensity was compared. The image amplification was $200 \times$. Scale bar=50 $\mu \mathrm{m}$. 
Table I Associations of PSPCI Expression with Pathological Characteristics in NPC Patients

\begin{tabular}{|c|c|c|c|c|c|}
\hline Parameters & Category & $\begin{array}{l}\text { High PSPCI } \\
(n=64)\end{array}$ & $\begin{array}{l}\text { Low PSPCI } \\
(n=45)\end{array}$ & $x^{2}$ & $P$ \\
\hline Gender & $\begin{array}{l}\text { Male } \\
\text { Female }\end{array}$ & $\begin{array}{l}56 \\
8\end{array}$ & $\begin{array}{l}36 \\
9\end{array}$ & 1.129 & 0.299 \\
\hline Age (years) & $\begin{array}{l}\leq 50 \\
>50\end{array}$ & $\begin{array}{l}39 \\
25\end{array}$ & $\begin{array}{l}33 \\
12\end{array}$ & $\mathrm{I} .8 \mathrm{II}$ & 0.220 \\
\hline Pathohistological pattern & $\begin{array}{l}\text { WHO II } \\
\text { WHO III }\end{array}$ & $\begin{array}{l}3 \\
61\end{array}$ & $\begin{array}{l}1 \\
44\end{array}$ & 0.454 & 0.500 \\
\hline Clinical stage & $\begin{array}{l}\text { I } \\
\text { II } \\
\text { III } \\
\text { IV }\end{array}$ & $\begin{array}{l}4 \\
5 \\
31 \\
24\end{array}$ & $\begin{array}{l}1 \\
3 \\
18 \\
23\end{array}$ & 2.535 & 0.469 \\
\hline $\mathrm{T}$ classification & $\begin{array}{l}\text { TI-T2 } \\
\text { T3-T4 }\end{array}$ & $\begin{array}{l}24 \\
40\end{array}$ & $\begin{array}{l}15 \\
30\end{array}$ & 0.200 & 0.689 \\
\hline $\mathrm{N}$ classification & $\begin{array}{l}\text { No } \\
\text { NI-N3 }\end{array}$ & $\begin{array}{l}8 \\
56\end{array}$ & $\begin{array}{l}1 \\
44\end{array}$ & 3.684 & $0.038^{*}$ \\
\hline Recurrence & $\begin{array}{l}\text { No } \\
\text { Yes }\end{array}$ & $\begin{array}{l}56 \\
8\end{array}$ & $\begin{array}{l}45 \\
0\end{array}$ & 6.071 & $0.014^{*}$ \\
\hline Prognosis & $\begin{array}{l}\text { Death } \\
\text { Survival }\end{array}$ & $\begin{array}{l}12 \\
52\end{array}$ & $\begin{array}{l}2 \\
43\end{array}$ & 4.830 & $0.040 *$ \\
\hline Radiosensitivity & $\begin{array}{l}C R \text { or } P R \\
S D \text { or } P D\end{array}$ & $\begin{array}{l}55 \\
9\end{array}$ & $\begin{array}{l}45 \\
0\end{array}$ & 6.898 & $0.010^{*}$ \\
\hline
\end{tabular}

Note: $* P<0.05$.

Abbreviations: WHO, Word Health Organization; Low PSPCI, low level for PSPCI expression; High PSPCI, high level for PSPCI expression.

metastasis. ${ }^{14,26,30}$ Radio-resistance has been ascertained as a major factor restricting the therapeutic efficacy of NPC. ${ }^{13,31}$ Elucidation of the mechanisms of radioresistance is therefore of great value to improve the therapeutic efficacy of NPC. On the other hand, identifying prognostic biomarker may facilitate the prediction of response prior to treatment and guide the choice of treatment approaches in clinic setting, leading to improvement in the survival rate and life quality of patients.

PSPC1 is overexpressed in numerous tumors and associated with cancer progression and metastasis, serving as a predictor of prognosis. ${ }^{16,32}$ Whether PSPC1 is upregulated in NPC has not been investigated previously. In this study, we revealed for the first time that the expression level of PSPC1 was significantly higher in NPC than that in normal nasopharyngeal epithelia tissues. The 3-year OS, PFS and DMFS rate in the low PSPC1 group of NPC patients is significantly higher than that in PSPC1 overexpression group, indicating that the expression levels of PSPC1 in NPC may be a potential prognostic biomarker to identify patients with potentially unfavorable outcomes prior to the treatment, and these patients may benefit from a more intensive therapeutic regimen.

Previous studies indicated that PSPC1 upregulation was associated with poor survival. ${ }^{16,33}$ PSPC1 is frequently altered at the DNA level and upregulated at the RNA level in many cancer types, such as breast, lung and liver tumors. The expression of PSPC1 was correlated with poor patient outcomes and low survival rate. $^{16,24}$ Immunohistochemical analysis revealed that PSPC1-positivity in nuclear and cytoplasm was strongly associated with shorter overall survival of hepatocellular carcinoma patients. ${ }^{34}$ In a HCC cohort study, the nuclear PSPC1 positivity was associated with the absence of liver cirrhosis and cytoplasmatic positivity was 

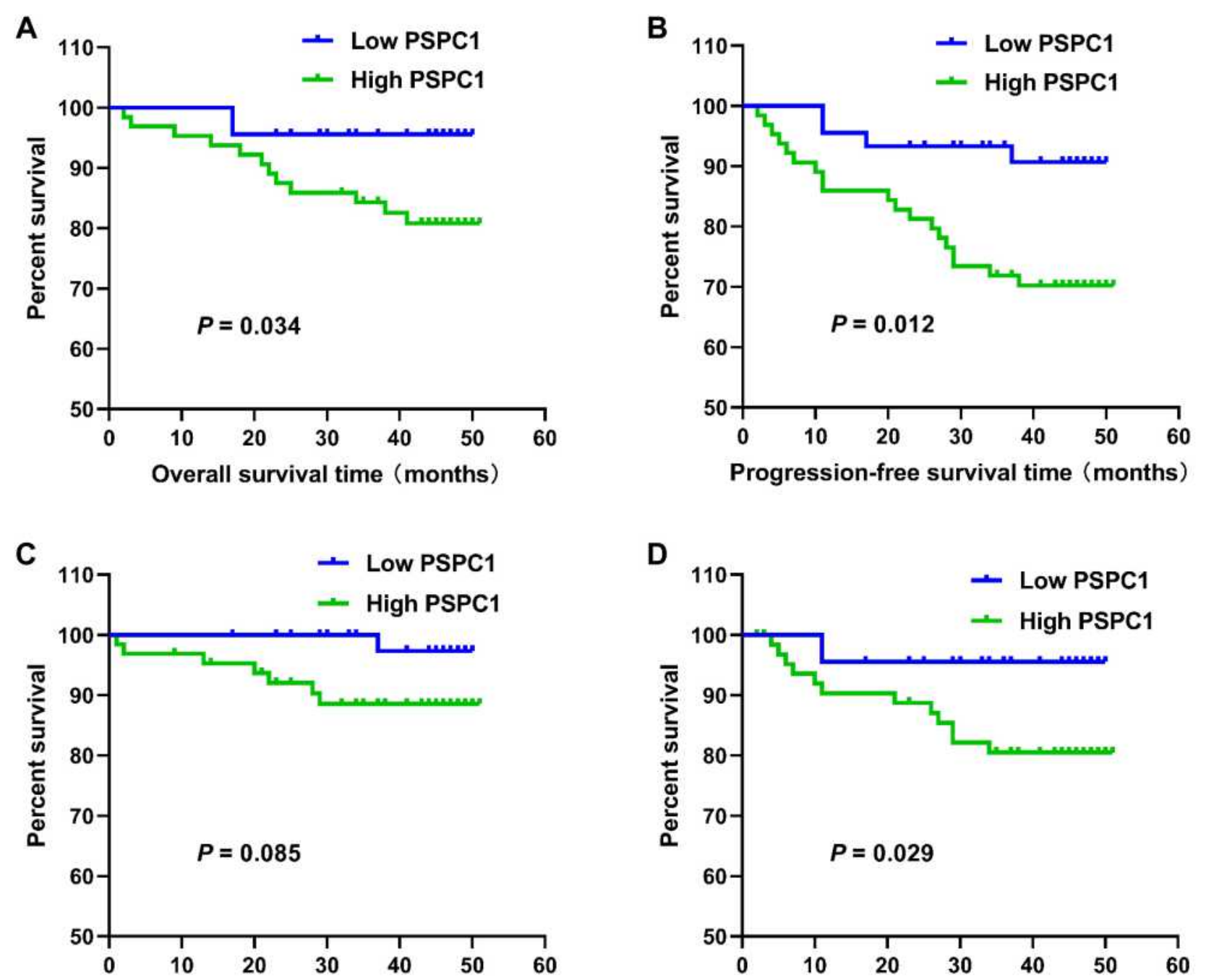

Locoregional recurrence-free survival time (months)

Distant metastasis-free survival time (months)

Figure 4 High PSPCI expression predicts inferior outcomes in NPC patients.

Notes: Survival data were analyzed and plotted using the Kaplan-Meier method. The NPC patients were classified into Low PSPCI or High PSPCI according to IHC score. (A) Overall Survival (OS). (B) Progression-free survival (PFS). (C) Locoregional recurrence-free survival (LRRFS). (D) Distant metastasis-free survival (DMFS).

associated with $\mathrm{HCV}$ infection. Interestingly, hepatitis delta virus (HDV) replication was shown to induce translocation of PSPC1 protein from the nucleus to the cytoplasm. $^{21}$ When PSPC1 was overexpressed in HCC cells, PSPC1 not only lost its sequestration of tumor suppression of PTK6 in the nucleus but also facilitated PTK6 cytoplasmic translocation to be an oncogene and $\beta$-catenin nuclear translocation to interact with PSPC1 for augmenting Wnt3a autocrine signaling and tumor progression. ${ }^{32}$ In breast and ovarian cancer, downregulation of PSPC1 enhanced cellular proliferation and might play a significant role with long non-coding RNAs (lncRNAs) NEAT1 and LSINCT5 in multiple processes. $^{35}$
In NPC, one of the major treatment failure is distant metastasis, which is linked to an unfavorable prognosis and survival. $^{36,37}$ Our results revealed that upregulation of PSPC1 was associated with poor patient's DMFS in NPC, the underlying mechanisms could be: 1) PSPC1 can enhance epithelial-mesenchymal transition (EMT), stemness and tumor growth through the activation of core transcription factors (TFs); ${ }^{16}$ 2) PSPC1 is also the interacting partner of $\operatorname{Smad} 2 / 3$, which acts as a contextual determinant of TGF- $\beta 1$ responses to switch the dichotomous TGF- $\beta 1$ function from tumor suppressing in precancerous cells to pro-metastatic signaling in malignant cancer cells. ${ }^{16,38}$

Local recurrence is another major treatment failure for NPC patients. ${ }^{39}$ PSPC1 is involved in both RNA synthesis 
Table 2 Correlation Between PSPCI Expression and 3-Year Outcomes in NPC Patients

\begin{tabular}{|l|l|l|l|l|}
\hline \multirow{2}{*}{ Rate (\%) } & High PSPCI & Low PSPCI & \multirow{2}{*}{$\mathbf{X}^{\mathbf{2}}$} & $\mathbf{P}$ \\
\cline { 2 - 3 } & $\mathbf{( n = 6 4 )}$ & $\mathbf{( n = 4 5 )}$ & & \\
\hline OS & 84.3 & 95.6 & 4.494 & $0.034^{*}$ \\
PFS & 71.9 & 93.3 & 6.365 & $0.012^{*}$ \\
LRRFS & 88.6 & 97.3 & 2.974 & 0.085 \\
DMFS & 80.5 & 95.6 & 4.746 & $0.029 *$ \\
\hline
\end{tabular}

Note: $* P<0.05$.

Abbreviations: High PSPCI, high level for PSPCI expression; Low PSPCI, low level for PSPCI expression; OS, overall survival; PFS, progression-free survival; LRRFS, locoregional recurrence-free survival; DMFS, distant metastasis-free survival.

and DNA repair. Knockdown of PSPC1 led to severe radio-sensitivity and delayed resolution of DSB repair foci. ${ }^{40}$ Our results suggested that patients with high expression of PSPC1 had a lower LRRFS than those of low expression. Further expansion of the number of cases and increased follow-up time might help to further verify the correlation between the PSPC1 overexpression and the patient's survival.

The univariate analysis results of this study indicated that gender, age, pathohistological pattern, clinical stage, $\mathrm{T}$ classification and $\mathrm{N}$ classification were not association with OS, PFS, LRRFS and DMFS of NPC patients, which could be due to the shorter follow-up time. Moreover, multivariate analysis had not proved that these factors were risk factors for OS, PFS, LRRFS and DMFS in patients with NPC. However, our results indicated that PSPC1 expression (high vs low) is the Independent prognosis factors associated with OS, PFS and DMFS of NPC patients. More research is needed to further clarify the correlation between these factors and patient's survival with extending the follow-up time and increasing the patient's cases.

\section{Conclusion}

In conclusion, our data showed that PSPC1 overexpression was correlated with NPC poor prognosis including shorter overall survival time, disease progression and distant metastasis. PSPC1 overexpression in tumors could be a potential biomarker for prognosis and a potential target for therapy. Future investigations, including prospective studies, are needed to further validate the value of PSPC1 overexpression in NPC prognosis. Cell culture studies and animal experiments are also desired to provide underlying mechanisms for understanding of the values of PSPC1 in cancer resistance, metastasis, and progression to radiation therapy.

Table 3 Univariate Log Rank Analyses of Prognostic Parameters of NPC

\begin{tabular}{|c|c|c|c|c|c|c|c|c|c|c|}
\hline \multirow[t]{2}{*}{ Parameters } & \multirow[t]{2}{*}{ Category } & \multirow[t]{2}{*}{ No. of Cases } & \multicolumn{2}{|c|}{ os } & \multicolumn{2}{|c|}{ PFS } & \multicolumn{2}{|c|}{ LRRFS } & \multicolumn{2}{|c|}{ DMFS } \\
\hline & & & Events & $P$ & Events & $P$ & Events & $P$ & Events & $P$ \\
\hline PSPCI expression & $\begin{array}{l}\text { High } \\
\text { Low }\end{array}$ & $\begin{array}{l}64 \\
45\end{array}$ & $\begin{array}{l}12 \\
2\end{array}$ & $0.034 *$ & $\begin{array}{l}19 \\
4\end{array}$ & $0.012^{*}$ & $\begin{array}{l}7 \\
1\end{array}$ & 0.085 & $\begin{array}{l}12 \\
2\end{array}$ & $0.029 *$ \\
\hline Gender & $\begin{array}{l}\text { Male } \\
\text { Female }\end{array}$ & $\begin{array}{l}92 \\
17\end{array}$ & $\begin{array}{l}12 \\
2\end{array}$ & 0.866 & $\begin{array}{l}21 \\
2\end{array}$ & 0.325 & $\begin{array}{l}7 \\
1\end{array}$ & 0.789 & $\begin{array}{l}13 \\
1\end{array}$ & 0.366 \\
\hline Age (years) & $\begin{array}{l}\leq 50 \\
>50\end{array}$ & $\begin{array}{l}72 \\
37\end{array}$ & $\begin{array}{l}7 \\
7\end{array}$ & 0.156 & $\begin{array}{l}12 \\
11\end{array}$ & 0.117 & $\begin{array}{l}3 \\
5\end{array}$ & 0.072 & $\begin{array}{l}8 \\
6\end{array}$ & 0.397 \\
\hline Pathohistological pattern & $\begin{array}{l}\text { WHO\# II } \\
\text { WHO III }\end{array}$ & $\begin{array}{l}4 \\
105\end{array}$ & $\begin{array}{l}0 \\
14\end{array}$ & 0.442 & $\begin{array}{l}1 \\
22\end{array}$ & 0.817 & $\begin{array}{l}0 \\
8\end{array}$ & 0.561 & $\begin{array}{l}1 \\
13\end{array}$ & 0.450 \\
\hline Clinical stage & $\begin{array}{l}\text { I } \\
\text { II } \\
\text { III } \\
\text { IV }\end{array}$ & $\begin{array}{l}5 \\
8 \\
49 \\
47\end{array}$ & $\begin{array}{l}0 \\
0 \\
7 \\
7\end{array}$ & 0.547 & $\begin{array}{l}0 \\
0 \\
10 \\
13\end{array}$ & 0.246 & $\begin{array}{l}0 \\
0 \\
5 \\
3\end{array}$ & 0.614 & $\begin{array}{l}0 \\
0 \\
6 \\
8\end{array}$ & 0.480 \\
\hline T classification & $\begin{array}{l}\text { TI-T2 } \\
\text { T3-T4 }\end{array}$ & $\begin{array}{l}39 \\
70\end{array}$ & $\begin{array}{l}4 \\
10\end{array}$ & 0.557 & $\begin{array}{l}6 \\
17\end{array}$ & 0.289 & $\begin{array}{l}2 \\
6\end{array}$ & 0.503 & $\begin{array}{l}4 \\
10\end{array}$ & 0.549 \\
\hline $\mathrm{N}$ classification & $\begin{array}{l}\text { N0 } \\
\text { NI-N3 }\end{array}$ & $\begin{array}{l}9 \\
100\end{array}$ & $\begin{array}{l}0 \\
14\end{array}$ & 0.236 & $\begin{array}{l}1 \\
22\end{array}$ & 0.442 & $\begin{array}{l}1 \\
7\end{array}$ & 0.691 & $\begin{array}{l}0 \\
14\end{array}$ & 0.235 \\
\hline
\end{tabular}

Notes: $* P<0.05$. Events: numbers of cases in OS, PFS, LRRFS or DMFS.

Abbreviations: WHO, Word Health Organization. 


\begin{tabular}{|c|c|c|c|c|c|}
\hline $\begin{array}{l}\text { 苋 } \\
\stackrel{\text { Oे }}{0}\end{array}$ & $\begin{array}{l}\text { o̊ } \\
\text { o. }\end{array}$ & $\stackrel{m}{\stackrel{m}{0}}$ & $\frac{\hat{f}}{0}$ & \begin{tabular}{l}
+ \\
\multirow{o}{0}{} \\
0
\end{tabular} & $\begin{array}{l}\stackrel{0}{\infty} \\
\stackrel{0}{0}\end{array}$ \\
\hline 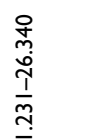 & 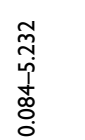 & $\begin{array}{l}\frac{n}{2} \\
\\
0 \\
0 \\
\frac{0}{0} \\
0 \\
0\end{array}$ & $\begin{array}{l}n \\
0 \\
0 \\
0 \\
\frac{1}{2} \\
0 \\
0\end{array}$ & $\begin{array}{l}\stackrel{0}{0} \\
\stackrel{0}{1} \\
0 \\
0 \\
0 \\
0\end{array}$ & 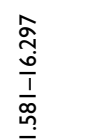 \\
\hline 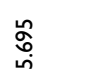 & $\begin{array}{l}\text { ণo } \\
\text { ¿. }\end{array}$ & $\stackrel{\hat{\sigma}}{\underline{\underline{a}}}$ & $\underset{\sim}{\stackrel{\sim}{N}}$ & 瑍 & $\begin{array}{l}\stackrel{n}{\hat{n}} \\
\hat{i}\end{array}$ \\
\hline$\frac{\widetilde{\sigma}}{0}$ & $\begin{array}{l}\stackrel{\circ}{\circ} \\
\stackrel{0}{0}\end{array}$ & $\frac{a}{0}$ & $\frac{m}{\hat{N}}$ & $\underset{\substack{\alpha \\
\infty \\
0}}{\infty}$ & $\begin{array}{l}\stackrel{n}{0} \\
0 \\
0\end{array}$ \\
\hline 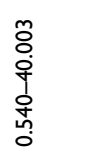 & $\begin{array}{l}\overline{\bar{\alpha}} \\
0 \\
0 \\
\bar{o} \\
\bar{o} \\
\end{array}$ & 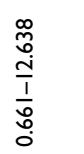 & 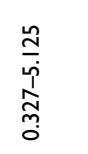 & 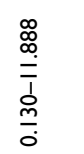 & 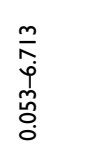 \\
\hline 吕 & م̂ & 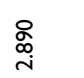 & 旁 & $\stackrel{\text { I }}{\underset{I}{+}}$ & 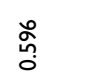 \\
\hline $\begin{array}{l}\stackrel{*}{\circ} \\
\stackrel{*}{\circ}\end{array}$ & ָّ̊ & $\stackrel{\stackrel{p}{\text { m }}}{\circ}$ & $\begin{array}{l}\text { nồ } \\
\text { o. }\end{array}$ & 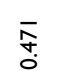 & ָ̊. \\
\hline 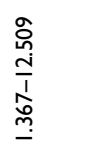 & 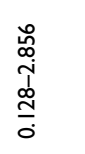 & 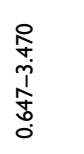 & $\begin{array}{l}\hat{\alpha} \\
0 \\
0 \\
0 \\
o \\
o \\
0\end{array}$ & $\begin{array}{l}\overline{\mathbf{T}} \\
\text { T. } \\
\underline{\underline{0}} \\
0\end{array}$ & 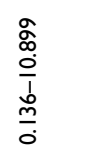 \\
\hline$\frac{\stackrel{m}{m}}{\dot{r}}$ & 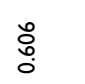 & 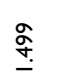 & $\underset{\mathrm{O}}{\mathrm{i}}$ & $\frac{\infty}{0}$ & $\stackrel{\stackrel{n}{ }}{\underline{I}}$ \\
\hline $\begin{array}{l}\stackrel{*}{\tilde{N}} \\
\stackrel{0}{0}\end{array}$ & $\begin{array}{l}\text { O̊ } \\
\text { O. }\end{array}$ & 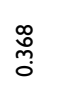 & $\frac{\frac{\infty}{m}}{0}$ & 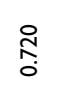 & $\begin{array}{l}\cong \\
\stackrel{\infty}{\circ} \\
0\end{array}$ \\
\hline 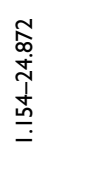 & $\begin{array}{l}\stackrel{p}{1} \\
\hat{p} \\
0 \\
0 \\
0 \\
0\end{array}$ & $\begin{array}{l}\stackrel{2}{0} \\
\stackrel{0}{0} \\
0 \\
0 \\
0 \\
0\end{array}$ & 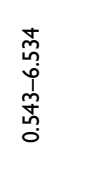 & 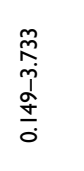 & 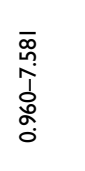 \\
\hline $\begin{array}{l}\stackrel{\hat{m}}{n} \\
\stackrel{n}{n}\end{array}$ & 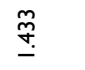 & 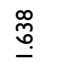 & 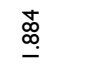 & $\underset{\substack{\stackrel{2}{0} \\
0}}{ }$ & $\begin{array}{l}\infty \\
\stackrel{\infty}{0} \\
i\end{array}$ \\
\hline 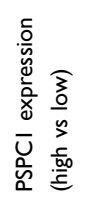 & 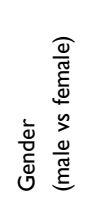 & 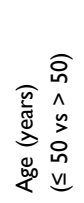 & 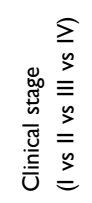 & 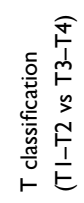 & 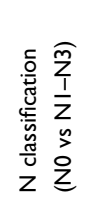 \\
\hline
\end{tabular}

\section{Abbreviations}

PSPC1, Paraspeckle component 1; NPC, Nasopharyngeal carcinomas; OS, Overall survival; DMFS, Distant metastasis-free survival; PFS, Progression-free survival; LRRFS, Locoregional recurrence-free survival; IMRT, Intensitymodulated radiotherapy; MRI, Magnetic resonance imaging; ECT, Emission computed tomography; PET, Positron emission tomography; AJCC, American joint committee on cancer; IHC, Immunohistochemical; Low PSPC1, low level of PSPC1 expression; High PSPC1, high level of PSPC1 expression; EDTA, Ethylenediaminetetraacetic acid; HRP, Horseradish Peroxidase; CTV, Clinical tumor volume; ESC, Esophageal squamous cell carcinoma; GTV, Gross tumor volumes; PTV, Planning tumor volume; Normal, Nasopharyngeal epithelial tissues; RS-NPC, Radiosensitive NPC; RR-NPC, Radioresistant NPC; RNA, Ribonucleic acid; DNA, Deoxyribonucleic acid.

\section{Acknowledgments}

This study was supported by National Natural Science Foundation of China (Grant no. 81974482), Natural Science Foundation of Fujian province (Grant no. 2019J01191, 2018J01732 and 2018J01275), Fujian Provincial Health Technology Project (Grant no. 2019CXB-8). Authors thank Dr. Shimin Zhang from Joint Pathology center, Silver Spring, USA for his scientific correction and Ms. Daisy E. Johnson for her English editing.

\section{Author Contributions}

All authors made a significant contribution to the work reported, whether that is in the conception, study design, execution, acquisition of data, analysis and interpretation, or in all these areas; took part in drafting, revising or critically reviewing the article; gave final approval of the version to be published; have agreed on the journal to which the article has been submitted; and agree to be accountable for all aspects of the work.

\section{Disclosure}

The authors declare that they have no conflicts of interest.

\section{References}

1. Chua MLK, Wee JTS, Hui EP, Chan ATC. Nasopharyngeal carcinoma. Lancet. 2016;387(10022):1012-1024. doi:10.1016/S0140-6736(15) 00055-0

2. Tang LL, Chen WQ, Xue WQ, et al. Global trends in incidence and mortality of nasopharyngeal carcinoma. Cancer Lett. 2016;374 (1):22-30. doi:10.1016/j.canlet.2016.01.040 
3. Wei KR, Zheng RS, Zhang SW, Liang ZH, Li ZM, Chen WQ. Nasopharyngeal carcinoma incidence and mortality in China, 2013. Chin J Cancer. 2017;36(1):90. doi:10.1186/s40880-017-0257-9

4. Caponigro F, Longo F, Ionna F, Perri F. Treatment approaches to nasopharyngeal carcinoma: a review. Anticancer Drugs. 2010;21 (5):471-477. doi:10.1097/CAD.0b013e328337160e

5. Zhang L, Chen QY, Liu H, Tang LQ, Mai HQ. Emerging treatment options for nasopharyngeal carcinoma. Drug Des Devel Ther. 2013;7:37-52. doi:10.2147/DDDT.S30753

6. Lee AW, Ma BB, Ng WT, Chan AT. Management of nasopharyngeal carcinoma: current practice and future perspective. J Clin Oncol. 2015;33(29):3356-3364. doi:10.1200/JCO.2015.60.9347

7. Lin S, Pan J, Han L, et al. Update report of nasopharyngeal carcinoma treated with reduced-volume intensity-modulated radiation therapy and hypothesis of the optimal margin. Radiother Oncol. 2014;110(3):385-389. doi:10.1016/j.radonc.2014.01.011

8. Zhang MX, Li J, Shen GP, et al. Intensity-modulated radiotherapy prolongs the survival of patients with nasopharyngeal carcinoma compared with conventional two-dimensional radiotherapy: a 10-year experience with a large cohort and long follow-up. Eur $J$ Cancer. 2015;51(17):2587-2595. doi:10.1016/j.ejca.2015.08.006

9. Kam MK, Wong FC, Kwong DL, Sze HC, Lee AW. Current controversies in radiotherapy for nasopharyngeal carcinoma (NPC). Oral Oncol. 2014;50(10):907-912. doi:10.1016/j.oraloncology.2013.09.013

10. Perri F, Della Vittoria Scarpati G, Caponigro F, et al. Management of recurrent nasopharyngeal carcinoma: current perspectives. Onco Targets Ther. 2019;12:1583-1591. doi:10.2147/OTT.S188148

11. Liu SC, Tsang NM, Chiang WC, et al. Leukemia inhibitory factor promotes nasopharyngeal carcinoma progression and radioresistance. J Clin Invest. 2013;123(12):5269-5283. doi:10.1172/JCI63428

12. Qu C, Zhao Y, Feng G, et al. RPA3 is a potential marker of prognosis and radioresistance for nasopharyngeal carcinoma. J Cell Mol Med. 2017;21(11):2872-2883. doi:10.1111/jcmm.13200

13. Chen YP, Chan ATC, Le QT, Blanchard P, Sun Y, Ma J. Nasopharyngeal carcinoma. Lancet. 2019;394(10192):64-80. doi:10.1016/S0140-6736(19)30956-0

14. Chen W, Hu GH. Biomarkers for enhancing the radiosensitivity of nasopharyngeal carcinoma. Cancer Biol Med. 2015;12(1):23-32. doi:10.7497/j.issn.2095-3941.2014.0015

15. Fox AH, Lam YW, Leung AK, et al. Paraspeckles: a novel nuclear domain. Curr Biol. 2002;12(1):13-25. doi:10.1016/s0960-9822(01) 00632-7

16. Yeh HW, Hsu EC, Lee SS, et al. PSPC1 mediates TGF- $\beta 1$ autocrine signalling and Smad2/3 target switching to promote EMT, stemness and metastasis. Nat Cell Biol. 2018;20(4):479-491. doi:10.1038/ s41556-018-0062-y

17. Sasaki YT, Ideue T, Sano M, Mituyama T, Hirose T. MENepsilon/ beta noncoding RNAs are essential for structural integrity of nuclear paraspeckles. Proc Natl Acad Sci U S A. 2009;106(8):2525-2530. doi:10.1073/pnas.0807899106

18. Gao X, Kong L, Lu X, et al. Paraspeckle protein 1 (PSPC1) is involved in the cisplatin induced DNA damage response-role in G1/S checkpoint. PLoS One. 2014;9(5):e97174. doi:10.1371/journal.pone.0097174

19. Chen LL, Carmichael GG. Altered nuclear retention of mRNAs containing inverted repeats in human embryonic stem cells: functional role of a nuclear noncoding RNA. Mol Cell. 2009;35 (4):467-478. doi:10.1016/j.molcel.2009.06.027

20. Wang J, Rajbhandari P, Damianov A, et al. RNA-binding protein PSPC1 promotes the differentiation-dependent nuclear export of adipocyte RNAs. J Clin Invest. 2017;127(3):987-1004. doi:10.1172/ JCI89484
21. Gao X, Zhang G, Shan S, et al. Depletion of Paraspeckle Protein 1 enhances methyl methanesulfonate-induced apoptosis through mitotic catastrophe. PLoS One. 2016;11(1):e0146952. doi:10.1371/journal. pone. 0146952

22. Wang Z, Fan P, Zhao Y, et al. NEAT1 modulates herpes simplex virus-1 replication by regulating viral gene transcription. Cell Mol Life Sci. 2017;74(6):1117-1131. doi:10.1007/s00018-016-2398-4

23. Guallar D, Bi X, Pardavila JA, et al. RNA-dependent chromatin targeting of TET2 for endogenous retrovirus control in pluripotent stem cells. Nat Genet. 2018;50(3):443-451. doi:10.1038/s41588-018-0060-9

24. Lang YD, Chen HY, Ho CM, et al. PSPC1-interchanged interactions with PTK6 and $\beta$-catenin synergize oncogenic subcellular translocations and tumor progression. Nat Commun. 2019;10(1):5716. doi:10.1038/s41467-019-13665-6

25. Kummoona R, Mohammad Sámi S, Al-Kapptan I, Al-Muala H. Study of antiapoptotic gene of oral carcinoma by using Bcl-2 oncogene. J Oral Pathol Med. 2008;37(6):345-351. doi:10.1111/ j.1600-0714.2007.00624.x

26. Lin S, Pan J, Han L, Zhang X, Liao X, Lu JJ. Nasopharyngeal carcinoma treated with reduced-volume intensity-modulated radiation therapy: report on the 3-year outcome of a prospective series. Int J Radiat Oncol Biol Phys. 2009;75(4):1071-1078. doi:10.1016/j. ijrobp.2008.12.015

27. Al-Sarraf M, LeBlanc M, Giri PG, et al. Chemoradiotherapy versus radiotherapy in patients with advanced nasopharyngeal cancer: Phase III randomized Intergroup study 0099. J Clin Oncol. 1998;16 (4):1310-1317. doi:10.1200/JCO.1998.16.4.1310

28. Guigay J. Advances in nasopharyngeal carcinoma. Curr Opin Oncol. 2008;20(3):264-269. doi:10.1097/CCO.0b013e3282fad846

29. Yan H, Cao X, Wang J. Application of intensity-modulated radiation therapy in the treatment of nasopharyngeal carcinoma. Oncol Lett. 2017;14(6):7773-7776. doi:10.3892/ol.2017.7186

30. Chen X, Lei H, Liang Z, Li L, Qu S, Zhu X. Intensity-modulated radiotherapy controls nasopharyngeal carcinoma distant metastasis and improves survival of patients. Springerplus. 2016;5(1):1459. doi:10.1186/s40064-016-3117-1

31. Guo Y, Zhu XD, Qu S, et al. Identification of genes involved in radioresistance of nasopharyngeal carcinoma by integrating gene ontology and protein-protein interaction networks. Int $J$ Oncol. 2012;40(1):85-92. doi:10.3892/ijo.2011.1172

32. Lang YD, Jou YS. PSPC1: a contextual determinant of tumor progression. Mol Cell Oncol. 2020;7(2):1721253. doi:10.1080/ 23723556.2020 .1721253

33. Zhang Z, He T, Huang L, et al. Two precision medicine predictive tools for six malignant solid tumors: from gene-based research to clinical application. J Transl Med. 2019;17(1):405. doi:10.1186/ s12967-019-02151-8

34. Kessler SM, Hosseini K, Hussein UK, et al. Hepatocellular carcinoma and nuclear paraspeckles: induction in chemoresistance and prediction for poor survival. Cell Physiol Biochem. 2019;52 (4):787-801. doi:10.33594/000000055

35. Silva JM, Boczek NJ, Berres MW, Ma X, Smith DI. LSINCT5 is over expressed in breast and ovarian cancer and affects cellular proliferation. RNA Biol. 2011;8(3):496-505. doi:10.4161/rna.8.3.14800

36. Sun $\mathrm{X}, \mathrm{Su} \mathrm{S}$, Chen $\mathrm{C}$, et al. Long-term outcomes of intensity-modulated radiotherapy for 868 patients with nasopharyngeal carcinoma: an analysis of survival and treatment toxicities. Radiother Oncol. 2014;110(3):398-403. doi:10.1016/j. radonc.2013.10.020

37. Mao YP, Tang LL, Chen L, et al. Prognostic factors and failure patterns in non-metastatic nasopharyngeal carcinoma after intensity-modulated radiotherapy. Chin J Cancer. 2016;35(1):103. doi:10.1186/s40880-016-0167-2 
38. Yeh HW, Lee SS, Chang CY, Lang YD, Jou YS, New A. Switch for TGF $\beta$ in cancer. Cancer Res. 2019;79(15):3797-3805. doi:10.1158/ 0008-5472.CAN-18-2019

39. Hu J, Huang Q, Gao J, et al. Clinical outcomes of carbon-ion radiotherapy for patients with locoregionally recurrent nasopharyngeal carcinoma. Cancer. 2020;126(23):5173-5183. doi:10.1002/cncr.33197
40. Li S, Li Z, Shu FJ, Xiong H, Phillips AC, Dynan WS. Double-strand break repair deficiency in NONO knockout murine embryonic fibroblasts and compensation by spontaneous upregulation of the PSPC1 paralog. Nucleic Acids Res. 2014;42(15):9771-9780. doi:10.1093/ nar/gku650

\section{Publish your work in this journal}

Cancer Management and Research is an international, peer-reviewed open access journal focusing on cancer research and the optimal use of preventative and integrated treatment interventions to achieve improved outcomes, enhanced survival and quality of life for the cancer patient.
The manuscript management system is completely online and includes a very quick and fair peer-review system, which is all easy to use. Visit http://www.dovepress.com/testimonials.php to read real quotes from published authors. 